$\xi=-1$

\title{
Employers' perception on important employability skills in the manufacturing industry
}

\author{
Shiau Wei Chan ${ }^{1 *}$, M.F. Ahmad², Izzuddin Zaman³, Woan Shin Ko ${ }^{4}$ \\ ${ }^{1,2,4}$ Faculty of Technology Management and Business, Universiti Tun Hussein Onn Malaysia, 86400 Batu Pahat, Johor, Malaysia \\ ${ }^{3}$ Faculty of Mechanical and Manufacturing Engineering, Universiti Tun Hussein Onn Malaysia, Batu Pahat, Johor, Malaysia \\ *Corresponding author E-mail: swchan@uthm.edu.my
}

\begin{abstract}
Employability skills are among the important soft skills that should be acquired by employees in the industrial sector today. Unfortunately, Malaysian graduates do face obstacles when looking for employment upon graduation due to the absence of employability skills among them. The main aim of this study is to identify employers' perceptions of the most important employability skills in the manufacturing industry. The study is also aimed to determine the differences between the important employability skills from the perspective of employers based on their gender, their company's size, and types of companies in the manufacturing industry. In this study, a total of 182 employers from the manufacturing industry in Batu Pahat were chosen randomly. Questionnaires were administered to the employers. The data generated were statistically analysed using descriptive and inferential analyses. The analysis shows that employers' perception of the most important employability skills in manufacturing industry is communication skills. The independent variables chosen are gender, company size, and types of manufacturing sector, while the dependent variable is the perceptions of important employability skills in the manufacturing industry. Results show that the perceptions of important employability skills in the manufacturing industry have no significant difference according to employers' gender and type of manufacturing sector, but there is a significant difference for company size. This quantitative study provides key insights that enable future employees to have more understanding of the employment demand in the manufacturing industry nowadays and for employees to develop their employability skills before getting ready to enter the labour market.
\end{abstract}

Keywords: Perceptions; Employability Skills; Manufacturing Industry

\section{Introduction}

Malaysian graduates do face obstacles when looking for employment upon graduation due to the absence of employability skills among them (1). There is an issue which stated that many technical graduates lack employability skills, based on the previous research conducted nationally and internationally (2). In addition, Rasul et al(3) stated that the career development of a person and industrial productivity will be affected if there is an absence of employability skills. Hence, based on their views, employability skills are vital skills which employers look for among graduates. Based on insights, employability skills refer to a kind of nontechnical ability which every single person who works in the industrial field should acquire as it is vital as technical skills. The demand for more competent employees has increased due to globalization and the evolution of technology. Another finding by Ramlee(4) on the industrialization of Malaysia from the perception of employers and educators and on the role of vocational and technical education is that although technical graduates in our country have mastered technical skills, employers are still not satisfied with their employees who lack communication, interpersonal, motivational, critical thinking, problem solving and also entrepreneurship skills. A piece of certificate is no longer a guarantee of employability since we are living in a competitive world today. Unlike decades ago, the choices of employment offered in the graduating year were almost assured when enrolling in almost any professional program. Having basic knowledge on academic skills and good personal qualities are not the only concern for employers today in finding good workers as they also look for high employability skills. The types of manufacturing workers demanded by the market now are those who are more skillful and adaptable since there are a more advanced, computer-assisted manufacturing replacing the "old-line" (5).

A lot of studies on the employability skills of graduates have been carried out to determine the factors affecting the high incidence of unemployment occurring in Malaysia. However, only very few studies have been conducted on the requirement of employability skills which are highly demanded by employers to fulfil the need of the manufacturing industry. Thus, this study attempts to identify employers' perceptions on the important employability skills needed in Malaysia, particularly in the manufacturing industry. This study intends to let people know the type of employability skills they should acquire in order to be employed and survive in the manufacturing industry nowadays. In addition, there is a lack of studies that identify the differences in the important employability skills from the perspective of employers based on their gender, the company size and type of company. Hence, this study intends to determine the differences in the important employability skills from the perspective of employers based on the same variables. The findings will help improve employees' performance and decrease the graduate unemployment rate. This is because, through this study, graduates can identify the employability skills that they need to acquire to face the challenges of working in the manufacturing industry. 


\section{Literature Review}

\subsection{Employability Skills}

Soo and Juma'ayah ${ }^{3}$ defined employability skills as a kind of non-technical ability which every single person who works in the industrial field should acquire as it is vital as technical skills. employers are generally looking for graduates who possess employability skills, especially communication and interpersonal skills, skills in problem-solving, and the ability to adapt to all kinds of situations in the workplace. No matter what kind of job the employee has to perform, these employability skills can be considered as the underpinning skills applied across the board. Generally, previous studies revealed that employers search for certain types of employability skills, attitudes, and behaviours in their potential employees. Typically, most employers prefer employees who have competencies such as able to possess the basic skills and perform personal management effectively, have individual responsibility, and have interpersonal and teamwork skills to negotiate, thus making them effective work group members, are motivated, selfmanaged, have integrity and higher performance standards, are able to adapt to creative thinking and skills in problem-solving, and influence others in the workplace through their leadership skills (6).

Chang(7), declared that a degree is no longer a guarantee for graduates to get hired for their first job automatically, which has become the main reason for graduates being unemployed nowadays. Instead, graduates who are able to acquire the greatest knowledge and skills in their study domain have the primary opportunity to secure the first employment. Furthermore, computerization has made job performance measurement very transparent as it changes the business world to become very competitive today. Employers only focus and are willing to recruit talented employees who have the competency of making a contribution to the team success. Employability skills which are sought after by employers are good communication and interpersonal skills, proficiency in English language, ability to speak up in a constructive manner, ability to identify and state issues and problems, resolve problems, present ideas, and analyse issues and problems that the company is currently facing and come up with effective solutions which could really help the company in resolving the problems. Therefore, starting from day one of being hired, employees are expected to contribute themselves (7). Other than that, employability skills such as good communication and team working skills are being recognized as the graduate skills consistently most wanted by employers in the current developed economies (8); Council for Industry and Higher Education (9); Australian Association of Graduate Employers

\subsection{Employers' Perceptions of the Importance of Em- ployability Skills}

According to(10), employers seek for employees who are good communicators. Furthermore, solid verbal communication skills must be acquired by employees in order to be effective at their respective workplace (10). In addition, organizations are able to function smoothly and productively with effective communication serving as a lubricant (11). The list of qualities that employers are looking for in the entry-level jobs also includes the executive and blue-collar positions and communication skills, including listening skills being at the top of the list $(11,12)$. According to $(13)$, communication skills are very important because they are targeted to support operations in the workplace every day as the capacity to gain commitment, establish rapport, and be persuasive is all highly valued in such settings. Communication skills in the workplace as defined by (14) are first, the ability in using the form of memos, letters, and reports to write and present information. Second, meetings and team assignments with colleagues should be engaged Third are communication skills involving directing, motivating, guiding, and evaluating individuals. Fourth, communication skills are needed in promoting to potential clients about the organization via face-to-face, e-mail, written and visual presentation, and telephone. Besides that, leadership skills can be described as leverage of the strengths of other people to realise the common objective and use of interpersonal skills to guide and develop others (8).

Interpersonal skills can be defined as the skills needed to work well with other people such as peers, subordinates and also superiors to understand their needs and also to be sympathetic to them (15). Teamwork is defined as the ability to function well in multidisciplinary teams, work effectively with others, demonstrate flexibility and adaptability, and also understand and contribute to the objectives of an organization(16). In the contemporary workplace, teams, committees, and workgroups are elemental to make a contribution to the success of every routine assignment, initiatives, and projects (17). Furthermore, information, communication, and technology skills are defined as the skills and competencies that facilitate the utilization of computers and interconnected information technologies to meet personal, educational and labour market targets (18). Additionally, Casner-Lotto and Barrington (8) described information, communication and technology skills as the ability to select and practice applicable technology to get a given task done successfully and implement the computing skills to problem-solving.

In a report by the Department of Education, Employment and Workplace Relations (19), English language proficiency is defined as the capability of students using the English language to demonstrate and communicate in both the written and spoken contexts during the completion of their university studies. The application can be ranged from a simple task, for example, in discussing duties with other students to more challenging tasks like giving a speech to a professional audience or writing an academic paper. Moreover, Rasul et al. (13) claimed that an employee with problem-solving skills has the capability of performing proper creative or innovative reasoning, problem-solving and decision-making skills. In addition, problem-solving skills are defined as the ability to solve workplace problems using data, knowledge, and facts by exercising sound reasoning, analytical thinking and applying math and science concepts (8). Adaptability skills are a sought-after job skill as employers increasingly rely more on flexible job descriptions and also rotate employees into different roles. The competencies of employees in getting used to different kinds of situations and expectations make them become more valuable to the current or prospective employer. It could also empower employees to be more equipped for different types of job opportunities (20). Besides that, according to Kristan (21), time management skills are the capability of a person that refuses to run away from difficulties and is able to engage them efficiently at the same time, and is also able to carefully, consciously, and purposefully take charge. Moreover, Coplin (10). explained that time management skills involve the competencies of a person in handling multiple assignments over a two or three-week period without missing any highly routine activities such as submitting weekly reports.

\subsection{Three Elements for the Employability Skills Per- ceived by Employers}

There was a survey carried out by Nabi and Bagley (22) at the University of Central Lancashire, UK. They found that there was a difference between the perception of male and female respondents towards the importance and quality of employability skills. Based on the findings, the quality of communication skills and problemsolving competencies were rated more important by male respondents compared to the females who rated the rest of the skills as more important. This difference was especially obvious for time management skills, flexibility, planning or organising skills, listening and information and technology skills. Nevertheless, there were several employability skills that female respondents rated higher compared to the males such as time management skills, team working, prioritising skills and planning or organising skills. Nabi and Bagley (22) further explained in their research that by considering the current parental upbringing and societal pressure, 
the different social roles and values for both genders have been strengthened, resulting in gender differences found in the research. However, there was another research which studied the important employability skills as perceived by employers from different genders, which found that there was no notable difference in the relation between employability skills and gender of the employers, leading to the conclusion by the authors that the opinions on graduates' employability skills are about the same for both male and female groups (23).

All skills and capabilities listed in the survey carried out by the Gallup Organization that were at least rather important when recruiting higher education graduates were agreed upon by graduate recruiters across all types of companies. In terms of rating certain skills and capabilities as "very important", foreign language skills are more likely to be highlighted as one of the important skills by graduate recruiters in medium-sized companies (34\% vs. $28 \%$ ), while large companies highlight the importance of communication skills more often compared to the smaller sized companies $(63 \%$ vs. $60 \%$ in medium-sized companies) and the ability to be able to adapt to new situations (62\% vs. $59 \%$ ). Based on the research conducted by Rasul et al. (24), amongst the three different types of company sizes which are small, medium and large companies, the large sized companies treat the acquisition of employability skills more than the requirement for their workers compared to smaller size companies. The specific employability skills considered very important by all employers regardless of size are interpersonal and thinking skills, and personal qualities. These skills are considered most important to be mastered by employees as a preparation before they enter the real labour world. Employers from large size companies chose interpersonal skills as the most important skill to be acquired by their employees. Moreover, within the interpersonal skills, employability skills of negotiating, providing customer service and exercising leadership are considered as the most important. Furthermore, informational skills which are needed mainly to maintain, interpret and disseminate information are categorized as moderately important to be acquired by employees (24).

A study carried out by a previous researcher found that there is a difference in the perception of dissimilar types of manufacturing sectors towards the important employability skills. The tests indicated that information and technology skills showed significant differences according to the types of companies. Meanwhile, the basic, thinking, resource, and interpersonal skills and personal qualities showed no significant difference between the types of manufacturing sector. This showed that the elements of information and technology skills are not so demanded by some of the employers in the different types of manufacturing sectors, for example, civil engineering industry due to the low requirement of information and technology skills while carrying out their work at their respective project sites(25) Furthermore, Rowley(26) found that there was a difference in the ranking by employers coming from different types of industrial sectors. The ranking result obtained vary depending on the specific industrial sector represented by the employer. For example, certain skills at a welding fabrication shop would be ranked as more important than the ranking at a farm credit office. Skills were chosen based on their applicability to most agricultural industrial sectors in Nevada County when developing the skills used in the research. However, the discrepancies in some of the rankings are most likely due to different job environments and skills needed in the career in the respective agricultural industrial sectors. However, a research conducted by Rasul et al. (2009)(24) found that employers in different types of sectors in the manufacturing industry are in consensus on the all seven employability skills. The mean score for each employer in the different types of manufacturing industry showed little difference and each of the means showed medium ranges of standard deviations, indicating a relatively small variability in the distribution (24).

\section{Methodology/Materials}

\subsection{Research Design}

A quantitative approach was used in this research, which included the activity of collecting numerical data from the target population Based on Creswell (27), the researcher used the post-positivist approach to develop a knowledge primary in selecting a quantitative research, for example, to study the cause and effect thinking, utilization of measurement and observations, and testing of various theories. It is also aimed to employ strategies of inquiry, for example, experiments and surveys, and collection of data using the predetermined instruments that yield statistical data. This study concentrates on obtaining the information needed and what can be measured. Furthermore, it involves data collection and analysis which are in the statistical or numerical descriptive data. Hence, the quantitative research was adopted in this research because it is suitable for the researcher to determine the level of importance for each of the employability skills listed as perceived by employers and identify the differences between the important employability skills from the perspective of employers based on their gender, the company size and type of manufacturing industry. The data collected and results obtained from the respondents were analysed quantitatively using the statistical software SPSS in order to attain the objectives of this research.

\subsection{Respondents}

Random sampling was used for this research based on Krejcie and Morgan's (28) table in determining the sample size. Simple random sampling is a basic sampling technique where a group of subjects (a sample) is selected for a study from a larger group (a population). According to Easton and McColl (29), each individual was chosen entirely by chance and each member of the population has an equal chance of being included in the sample. Every single possible sample of a given size has the same chance of getting to be selected. In this study, the targeted population was 400 employers in the manufacturing industry in Batu Pahat, Johor. A total of 182 respondents were chosen randomly from the target population.

\subsection{Instrumentation}

The questionnaire constructed for this research comprises two sections. Section A captures the demographic information of the respondents, while section $B$ requires employers to rate the level of importance for each of the employability skills listed with a three-point Likert Scale ranging from (1), "not so important", (2) "moderately important" and (3) "very important". The questionnaire was modified from (23). The questionnaires were collected and analysed using the Statistical Packages for Social Science (SPSS) version 20.0. A pre-test was conducted on 30 employers in the manufacturing industry to test the suitability of the questionnaire. The Cronbach's Alpha value for the pre-test was 0.712 which is considered as acceptable by (30).

\subsection{Data Analysis}

The results of this study were analysed using descriptive analysis. Descriptive analysis aims to explain the data and characteristics of the population or phenomenon being studied. The results generated from the descriptive analysis allow the researcher to determine the employability skills that are the most important to be acquired by the employees in the manufacturing industry based on the perception of employers by referring to the mean score. Besides that, the inferential analysis used involved the t-Test and ANOVA. The t-test was conducted to determine the differences between employability skills with gender. Meanwhile, ANOVA was utilized to identify whether there are any differences between employabil- 
ity skills based on the size and type of company in the manufacturing industry.

\section{Findings and Discussions}

\subsection{Level of Importance for Employability Skills in Manufacturing Industry}

The first objective of this study is to identify employers' perceptions on the most important employability skills in the manufacturing industry in Batu Pahat. The average mean scores were calculated for all the dimensions of employability skills in order to achieve this objective. Figure 1 shows the average mean scores of the seven employability skills being measured throughout the research. Communication skills were shown to have the highest mean score of 2.90 , followed by problem solving skills and adaptability skills at the second place with a mean score of 2.63. Interpersonal skills and ability to work as a team were at the third place with a mean score of 2.48 , while personal organization and time management skills, as well as English language proficiency attained the mean score of 2.34. Next were leadership skills with a mean score of 2.12, and lastly, information, communication and technology skills with a mean score of 1.91 .

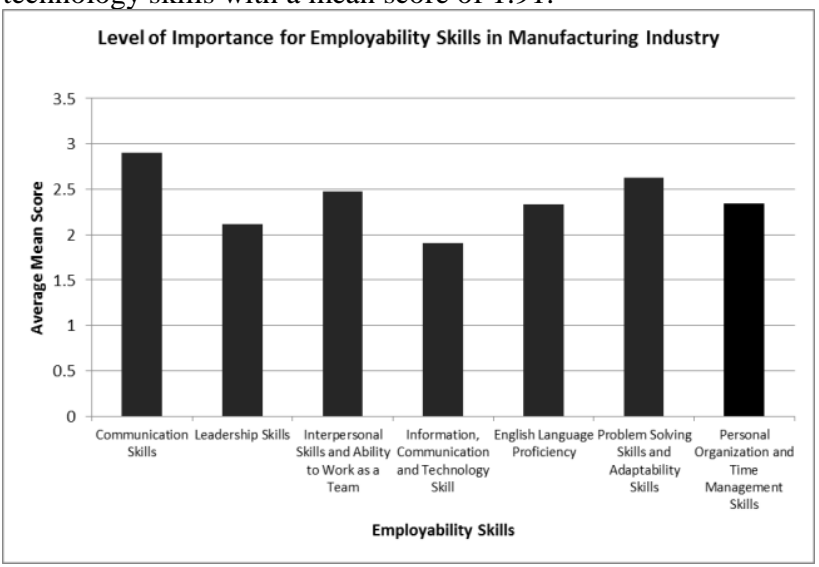

Fig 1: Level of Importance for Employability Skills in Manufacturing Industry

From the results, it was noticed that the most important employability skills perceived by employers in the manufacturing industry are communication skills. Based on the research carried out by Rasul et al. (13), communication skills also obtained a high score on its importance according to employers. Based on the many manufacturing industries' contexts, communication skills act as an important aspect, which means that employees need to be skilful in communicating with people from a variety of ethnic backgrounds and are able to use different forms of communication(31).

\subsection{Significant Difference of Gender of Employers to- wards the Perceptions of Importance Level of Employa- bility Skills in Manufacturing Industry}

The second objective of this study is to determine the differences in importance of the employability skills from the perspective of employers based on their gender, the company size and type of sector in the manufacturing industry in Batu Pahat. Determining the gender group was the first component needed to work on. To determine the gender of employers and their perceptions towards the important employability skills, an independent sample T-test was employed since there are only two groups of gender which are male and female. In an independent T-test result, a significant value of greater than 0.05 indicates that there is no statistically significant difference between each of the component. However, if the significant value is less than 0.05 , it means that there is a statistically significant difference between each of the component. According to the results in Table 1, most of the significant values were greater than 0.05 , which means that there is no significant difference between the employers' gender towards the perception of the importance of employability skills, except for English language proficiency, and problem-solving and adaptability skills. This result was supported by(32), and (23) where there was no significant difference between male and female respondents' rating in terms of employability skills. The result that shows a significant difference of employers' gender towards the perception of importance of employability skills was supported by a survey carried out by Nabi and Bagley (1998)(22) in the University of Central Lancashire, UK.

Table 1: T-Test for Gender group

\begin{tabular}{|l|l|c|c|c|}
\hline \multicolumn{2}{|l}{} & \multicolumn{2}{|l|}{$\begin{array}{c}\text { Levene's Test for } \\
\text { Equality of Variances }\end{array}$} & $\begin{array}{c}\text { t-test for Equality } \\
\text { of Means }\end{array}$ \\
\cline { 2 - 6 } & \multicolumn{2}{|l}{ F } & Sig. & Sig.(2-tailed) \\
\hline $\begin{array}{l}\text { Communication Skills } \\
\text { Mean }\end{array}$ & $\begin{array}{l}\text { Equal } \\
\text { variances } \\
\text { assumed }\end{array}$ & 16.138 & .000 & .055 \\
\hline Leadership Skills Mean & $\begin{array}{l}\text { Equal } \\
\text { variances } \\
\text { assumed }\end{array}$ & 5.547 & .020 & .617 \\
\hline $\begin{array}{l}\text { Interpersonal Skills and } \\
\text { Ability to Work as a } \\
\text { Team mean }\end{array}$ & $\begin{array}{l}\text { Equal } \\
\text { variances } \\
\text { assumed }\end{array}$ & .041 & .840 & .551 \\
\hline ICT Skills Mean & $\begin{array}{l}\text { Equal } \\
\text { variances } \\
\text { assumed }\end{array}$ & 4.177 & .042 & .146 \\
\hline $\begin{array}{l}\text { English Language Profi- } \\
\text { ciency Mean }\end{array}$ & $\begin{array}{l}\text { Equal } \\
\text { variances } \\
\text { assumed }\end{array}$ & 14.537 & .000 & .005 \\
\hline $\begin{array}{l}\text { Problem Solving Skills } \\
\text { and Adaptability Skills } \\
\text { Mean }\end{array}$ & $\begin{array}{l}\text { Equal } \\
\text { variances } \\
\text { assumed }\end{array}$ & 14.862 & .000 & .000 \\
\hline $\begin{array}{l}\text { Personal Organization } \\
\text { and Time Management } \\
\text { Skills Mean }\end{array}$ & $\begin{array}{l}\text { Equal } \\
\text { variances } \\
\text { assumed }\end{array}$ & .614 & .434 & \\
\hline
\end{tabular}

\subsection{Significant Difference of Size of Company towards the Perceptions of Importance Level of Employability Skills in Manufacturing Industry}

The second component determined was the size of the company. A One-Way ANOVA was used to determine the size of the company and its relation to the perception of importance of employability skills since there are more than two categories of company size, i.e. below 50 people, 50-99 people, 100-199 people, 200-499 people and more than 500 people. In the One-Way ANOVA result, a significant value greater than 0.05 means there is no statistically significant difference between each component. However, if the significant value is less than 0.05 , this means that there are statistically significant differences between each of the component. The result of the One-Way ANOVA displayed in Table 2 shows that there is a significant difference between company sizes on the perception of the importance of employability skills, except for communication skills. Results found by Rasul et al. (2009)(24) proved that there is a significant difference of company size towards the perception of importance of employability skills. They conducted the study on three types of company sizes which are small, medium and large and found that the importance of the acquisition of employability skills among workers was more emphasized in large-sized compared to the smaller-sized companies. Hence, the result obtained for the research was supported by a previous research. 


\begin{tabular}{|c|c|c|c|c|c|c|}
\hline & & Sum of squares & df & Mean square & $\mathbf{F}$ & Sig. \\
\hline \multirow{3}{*}{ Communication Skills } & Between Groups & .374 & 4 & .093 & 1.541 & .192 \\
\hline & Within Groups & 10.735 & 117 & .061 & & \\
\hline & Total & 11.109 & 181 & & & \\
\hline \multirow{3}{*}{ Leadership Skills } & Between Groups & 6.176 & 4 & 1.544 & 11.831 & .000 \\
\hline & Within Groups & 23.100 & 117 & .131 & & \\
\hline & Total & 29.276 & 181 & & & \\
\hline \multirow{3}{*}{ Interpersonal Skills and Ability to Work as a Team } & Between Groups & 4.406 & 4 & 1.101 & 15.224 & .000 \\
\hline & Within Groups & 12.806 & 117 & .072 & & \\
\hline & Total & 17.212 & 181 & & & \\
\hline \multirow{3}{*}{ Information, Communication and Technology Skill } & Between Groups & 2.048 & 4 & .512 & 2.599 & .038 \\
\hline & Within Groups & 34.879 & 117 & .197 & & \\
\hline & Total & 36.928 & 181 & & & \\
\hline \multirow{3}{*}{ English Language Proficiency } & Between Groups & 9.115 & 4 & 2.279 & 15.482 & .000 \\
\hline & Within Groups & 26.051 & 117 & .147 & & \\
\hline & Total & 35.166 & 181 & & & \\
\hline \multirow{3}{*}{ Problem Solving Skills and Adaptability Skills } & Between Groups & 12.258 & 4 & 3.065 & 29.390 & .000 \\
\hline & Within Groups & 18.456 & 117 & .104 & & \\
\hline & Total & 30.714 & 181 & & & \\
\hline \multirow{3}{*}{ Personal Organization and Time Management Skills } & Between Groups & 2.392 & 4 & .598 & 6.031 & .000 \\
\hline & Within groups & 17.549 & 117 & .099 & & \\
\hline & Total & 19.940 & 181 & & & \\
\hline
\end{tabular}

Table 3: ANOVA Test for the Type of Manufacturing Sector

\begin{tabular}{|c|c|c|c|c|c|c|}
\hline & & Sum of squares & df & Mean square & $\mathbf{F}$ & Sig. \\
\hline \multirow{3}{*}{ Communication Skills } & Between Groups & .324 & 4 & .081 & 1.331 & .26 \\
\hline & Within Groups & 10.784 & 117 & .061 & & \\
\hline & Total & 11.109 & 181 & & & \\
\hline \multirow{3}{*}{ Leadership Skills } & Between Groups & 1.493 & 4 & .373 & 2.377 & .054 \\
\hline & Within Groups & 27.784 & 117 & .157 & & \\
\hline & Total & 29.276 & 181 & & & \\
\hline \multirow{3}{*}{$\begin{array}{l}\text { Interpersonal Skills and Ability to Total Work as a } \\
\text { Team }\end{array}$} & Between Groups & .856 & 4 & .214 & 2.317 & .059 \\
\hline & Within Groups & 16.356 & 117 & .092 & & \\
\hline & Total & 17.212 & 181 & & & \\
\hline \multirow{3}{*}{ Information, Communication and Technology Skill } & Between Groups & .296 & 4 & .074 & .358 & .838 \\
\hline & Within Groups & 36.631 & 117 & .207 & & \\
\hline & Total & 36.928 & 181 & & & \\
\hline \multirow{3}{*}{ English Language Proficiency } & Between Groups & 3.100 & 4 & 775 & 4.277 & .003 \\
\hline & Within Groups & 32.066 & 117 & .181 & & \\
\hline & Total & 35.166 & 181 & & & \\
\hline \multirow{3}{*}{ Problem Solving Skills and Adaptability Skills } & Between Groups & 2.681 & 4 & .670 & 4.232 & .003 \\
\hline & Within Groups & 28.033 & 117 & .158 & & \\
\hline & Total & 30.714 & 181 & & & \\
\hline \multirow{3}{*}{ Personal Organization and Time Management Skills } & Between Groups & .180 & 4 & .045 & .404 & .806 \\
\hline & Within groups & 19.760 & 117 & .112 & & \\
\hline & Total & 19.940 & 181 & & & \\
\hline
\end{tabular}

\subsection{Significant Difference of Type of Manufacturing Sector towards the Perceptions of Importance Level of Employability Skills in Manufacturing Industry}

The third component to be examined was the types of the manufacturing sector. The One-Way ANOVA was utilized to determine the types of the manufacturing sector and their relation to the perceptions towards the important level of employability skills as there were more than two groups of manufacturing sector types, namely, textile, food, electric, furniture, and other manufacturing sectors. From the result of the One-Way ANOVA in Table 3, it was noticed that there was no significant difference for the type of manufacturing sector towards the perception of importance for most of the employability skills except for English language proficiency and problem-solving and adaptability skills. This result was supported by research conducted by(25), where most of the employability skills showed no significant difference by the type of company in the research. However, there was another research conducted by(26), who obtained different rankings from different employers coming from different types of industrial sector. The specific industrial sector had a big impact on the ranking result. For example, certain skills at a farm credit office were ranked lower than at a welding fabrication in terms of importance.

\section{Conclusion}

The analysis showed that communication skills have the highest mean value. This shows that all employers place this employability skill as the most crucial skill to be possessed by all graduates to enable them to compete in the global market. In addition, the independent sample T-test presented that there was no significant difference in the gender of employers towards their perception of important employability skills. The One-Way ANOVA displayed that there was a significant difference for company size towards the perception of important employability skills. Furthermore, the One-Way ANOVA indicated that there was no significant difference for the type of manufacturing sector towards the perception of important employability skills. This study allows people to understand the type of employability skills that should be acquired to make an effort to employ and survive in the manufacturing industry according to the needs nowadays. The results of the findings can serve as a useful guide for educational institutions or educators to design specific development programs, curriculum, and co-curriculum for students. This could enhance their employability skills that are considered as important and should be acquired by students before entering the real labour world in the 
future. In addition, similar future research may be carried out in different contexts such as extending the scope of the target to different kinds of the sector in Malaysia to be compared with the results of this research.

\section{Acknowledgement}

This work was supported by Universiti Tun Hussein Onn Malaysia under Grant No. U431.

\section{References}

[1] Shafie LA, Nayan S. Employability awareness among Malaysian undergraduates. International Journal of Business and Management. 2010;5(8):119.

[2] Rasul MS, Rauf R, Mansor A, Yasin R, Mahamod Z, editors Importance of employability skills for technical and vocational students. The 3rd International Conference on Learner Diversity; 2012.

[3] Rasul MS, Rauf RAA, Nor ARM. Future Employability Skills Sets for Manufacturing Industries. International Education Studies. 2014;7(10): 138

[4] Mustapha RB. The role of vocational and technical education in the industrialization of Malaysia as perceived by educators and employers. 1999.

[5] Singleton D. Manufacturers are hiring again; what skills are they looking for. Software Advice Retrieved September. 2011;4:2011.

[6] Neal JAS. Secretary's Commission on Achieving Necessary Skills (SCANS) as viewed by the staff of Ethelene Jones Crockett Technical High School and Career and Technical Center. 1997.

[7] Chang M. Why some graduates are more marketable than others: Employers' perspective. Paper presented in a Workshop on Enhancing Graduate Employability in a Globalised Economy, July 2004. Economic Planning Unit, Malaysia. 2004

[8] Casner-Lotto J, Barrington L. Are They Really Ready to Work? Employers' Perspectives on the Basic Knowledge and Applied Skills of New Entrants to the 21st Century US Workforce: ERIC; 2006.

[9] Archer W, Davison J. Graduate Employability: what do employers think and want? Council for Industry and Higher Education. 2008.

[10] Honaker SL. 10 Things Employers Want You to Learn in College: The Know-how You Need to Succeed. Journal of College Student Development. 2005;46(3):333-4.

[11] Woods RH, King JZ. Leadership and management in the hospitality industry: Educational Inst of the Amer Hotel; 2002.

[12] McKay J. Employers complain about communication skills. Pittsburgh Post-Gazette (February). 2005.

[13] Rasul MS, Rauf RAA, Mansor AN, Yasin RM, Mahamod Z. Graduate employability for manufacturing industry. ProcediaSocial and Behavioral Sciences. 2013;102:242-50.
[14] Chaney L, Martin J. Intercultural business communication: Pearson Higher Ed; 2013.

[15] Evers FT, Rush JC, Berdrow I. The Bases of Competence. Skills for Lifelong Learning and Employability: ERIC; 1998.

[16] Cates C, Cedercreutz K. Leveraging cooperative education to guide curricular innovation: the development of a corporate feedback system for continuous improvement: Center for Cooperative Education Research and Innovation, University of Cincinnati; 2008.

[17] Dunne E, Rawlins M. Bridging the gap between industry and higher education: Training academics to promote student teamwork. Innovations in Education and Teaching International. 2000;37(4):361-71.

[18] Assessment L. Information and Communication Technology Literacy Assessment Framework. 2000.

[19] Agency AUQ. Good practice principles for English language proficiency for international students in Australian universities. 2009.

[20] Kokemuller N. The Concept of empowerment in leadership. 2007.

[21] Kristan P. Awakening in Time: Practical Time Management for Those on a Spiritual Path: Dog Ear Publishing; 2010.

[22] Nabi GR, Bagley D. Graduates' perceptions of transferable personal skills and future career preparation in the UK. Career Development International. 1998;3(1):31-9.

[23] Singh GKG, Singh SKG. Malaysian graduates' employability skills. UNITAR e-Journal. 2008;4(1):15-45.

[24] Rasul MS, Ismail MY, Ismail N, Rajuddin MR, Rauf RAA. Importance of employability skills as perceived by employers of Malaysian manufacturing industry. Journal of Applied Sciences Research. 2009;5(12):2059-66.

[25] Husain M, Mokhtar S, Ahmad A, Mustapha R. Importance of employability skills from employers' perspective. Procedia Social and Behavioural Sciences, 7 (c), 430-438. 2010.

[26] Rowley C. Student and employer perceptions of the importance of entry-level employability skills 2014

[27] Creswell JW, Plano Clark VL, Gutmann ML, Hanson WE Advanced mixed methods research designs. Handbook of mixed methods in social and behavioral research. 2003;209:240.

[28] Krejcie RV, Morgan DW. Determining sample size for research activities. Educational and psychological measurement 1970;30(3):607-10

[29] Easton VJ, McColl JH. Statistics glossary: Steps; 1997.

[30] Uma S, Roger B. Research methods for business: A skill building approach. book. 2003.

[31] McLeish A. Employability skills for Australian small and medium sized enterprises: report of the interviews and focus groups with small and medium enterprises: Department of Education, Science and Training; 2002.

[32] Chithra R. Employability Skills-A Study on the perception of the Engineering Students and their Prospective Employers. Global Journal of Management and Business Studies. 2013;3(5):525-34. 